\title{
A cerebral hemisphere influence on cutaneous vasomotor reflexes in humans
}

\author{
A-G Herbaut, J D Cole, E M Sedgwick
}

\begin{abstract}
Cutaneous vasomotor reflexes (CVR), the transient waves of cutaneous vasoconstriction after stimuli, such as a cough, were recorded from the digits of patients with unilateral frontoparietal lesions using a laser doppler flowmeter. Vasoconstriction was 6-15 times greater on the fingers contralateral to the lesions, an effect which was independent of the temperature difference between limbs. CVRs may be tonically inhibited under normal circumstances by control from the cerebral hemispheres.
\end{abstract}

Following a deep inspiration or cough a wave of vasoconstriction occurs in the limbs which may be measured by digit volume plethysmography. 'These cutaneous vasomotor reflexes (CVR) are present even after complete cervical cord lesions and so are spinally mediated ${ }^{2}$ and require an intact thoracic cord. ${ }^{23}$ Cole et al observed that the CVR in the fingers of tetraplegic subjects were increased compared with normal subjects despite the poor ability of tetraplegic patients to perform the provoking procedures. This suggested that there may be a descending inhibitory influence on these reflexes from higher centres. To test this hypothesis a group of patients with unilateral hemisphere lesions was studied.

Service de Neurologie, Hopital Erasme, Universite Libre de Bruxelles, Belgium A-G Herbaut

Wessex Neurological Centre, General Hospital,

Southampton

J D Cole

E M Sedgwick

Correspondence to:

Dr J D Cole, Department of Clinical Neurophysiology, Clinical Neurophysiology, Wessex Neurological Cen Southampton General Hospital, Shirley Southampton SO9 $4 \mathrm{XY}$ United Kingdom.

Received 1 March 1988 and in final revised form

25 August 1989 .

Accepted 7 September 1989

\section{Methods}

Vasomotor reflexes were measured by recording the total blood cell flux in a small volume of skin from the thumb using a laser doppler flowmeter (Periflux Pf2). ${ }^{4}$ The output from the flowmeter is a voltage proportional to total blood cell flux in a hemispheric volume of tissue about $1 \mathrm{~mm}$ in radius beneath the probe head. Beat to beat variations in flux are recorded as well as longer term changes.

The study involved 30 patients, 17 female and 13 male, aged 33-80 years, of whom 25 showed the effect to be described. All gave their informed consent to the procedure which itself had the approval of the hospital ethical committee. Fourteen normal controls aged 19-65 years were also studied. Fifteen of the patients

Table 1 The effect of unilateral hemisphere lesions on skin temperature

\begin{tabular}{|c|c|c|c|}
\hline & $\begin{array}{l}\text { Ipsilateral } \\
\text { Temperature }{ }^{\circ} \mathrm{C} \\
\text { mean }(S D)\end{array}$ & $\begin{array}{l}\text { Contralateral } \\
\text { Temperature }{ }^{\circ} \mathrm{C} \\
\text { mean }(S D)\end{array}$ & $\begin{array}{l}\text { Difference }{ }^{\circ} \mathrm{C} \\
\text { mean }(S D)\end{array}$ \\
\hline $\begin{array}{l}\text { With motor signs } n=15 \\
\text { No motor signs } n=8\end{array}$ & $\begin{array}{l}29.6(1.9) \\
28.9(2.6)\end{array}$ & $\begin{array}{l}30 \cdot 8(1 \cdot 2) \\
28 \cdot 8(2 \cdot 0)\end{array}$ & $\begin{array}{l}1 \cdot 2(0 \cdot 7) \\
0 \cdot 1(1 \cdot 1)\end{array}$ \\
\hline
\end{tabular}

had unilateral frontal, fronto-parietal or capsular ischaemic lesions or unilateral frontal or fronto-parietal tumours. All had upper motor neuron signs of spasticity or, in three cases, flaccidity as they were seen in the five days following removal of hemisphere gliomas. Eight other patients had no clinical motor signs but had sensory signs, hemianopia or both. They were studied five days to one year after the onset of symptoms. Those patients receiving medication which may have interfered with autonomic function or those with possible autonomic defects, such as, peripheral neuropathy, were excluded.

The subjects were seated comfortably in a room of constant temperature $\left(23-25^{\circ} \mathrm{C}\right)$ and low ambient noise level. They had emptied their bladders before the procedure. The laser probe was attached to the pulp of the thumb and a stable baseline obtained. The subjects were asked to take a single rapid deep breath and later to give a single cough; each manoeuvre was repeated at 30 second intervals at least five times. A startle response was produced by making a sudden loud noise. The skin temperature of the thumbs was measured.

The reduction in blood flow was expressed as a percentage of resting flow and a mean value calculated for each monoeuvre. The ratios of the response of the contralateral side/ipsilateral side to the lesion were calculated. Their distribution was not normal and so a Wilcoxon's rank sum test was used to compare the mean ratio for each manoeuvre in patients with and without motor signs and in normal subjects, and the medians and ranges were given. The latencies of the CVR were also determined.

\section{Results}

Skin temperature of the side contralateral to the lesion was higher than on the ipsilateral side in those patients with motor signs but not in the others, paired $t$ test $\mathrm{p} \ll 0.001$ (table 1 ). In most patients with unilateral motor signs, the amplitude of the resting pulsatile waves over the affected limb was larger than on the ipsilateral side, suggesting skin arteriolar dilatation (fig 1A). In two patients the test was repeated on separate days. In each case the results were reproducible.

In patients with unilateral motor signs, the fall in blood flow following inspiration or cough or startle was $6-15$ times greater on the affected (contralateral) side than on the ipsilateral side. This was significantly different from the patients with no motor signs and from the normal subjects and was independent of 
Figure 1 a Reduction in skin blood flow after an inspiration in a woman of 80 years with left hemiplegia, left sensory loss and left homonymous hemianopia due to an extensive right hemisphere infarct. Beginning of inspiration $(\uparrow)$ : beginning of response (1). After effect is still more marked on the affected side $(1 \mathrm{~b})$.

Figure 2 Reduction in skin blood flow after an inspiration ( $a$ ) and $a$ startle manoeuvre $(b)$ in $a$ 68 year old woman with a left frontal glioma producing a right hemiplegia. Spontaneous vasoconstrictions were observed in the right thumb (c). Beginning of manoeuvre ( $\uparrow$ ); beginning of response (1). warming the hands the despite normal respiration
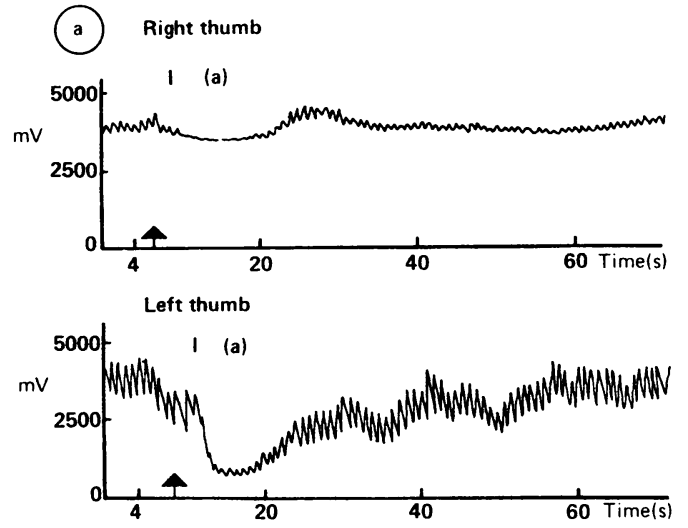

(b)

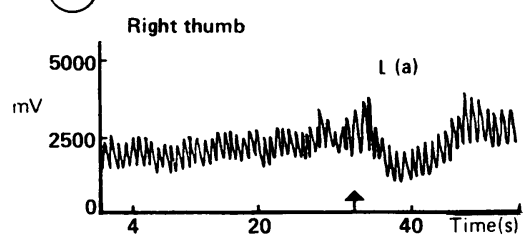

Left thumb

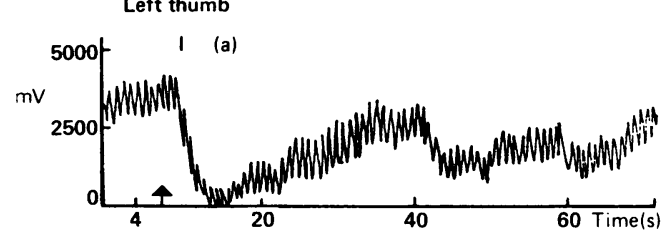

skin temperature, $\mathrm{p}<0.01$ Wilcoxon's rank sum test (fig $1 \mathrm{~A}, \mathrm{~B}, 2$, table 2 ). The latencies of the responses were similar on both sides; mean contralateral latency was 3.67 seconds and mean ipsilateral latency was 3.64 seconds. Spontaneous cutaneous vasoconstrictor episodes were observed on the contralateral but not on the ipsilateral side in some of the
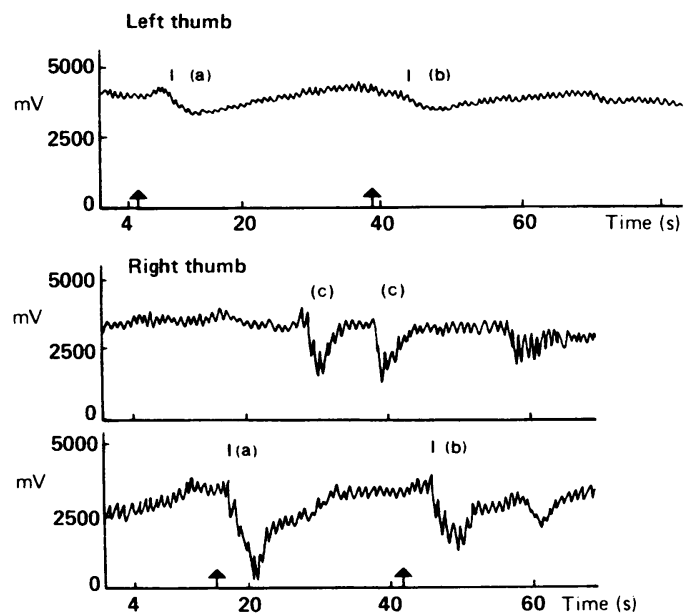

Table 2 Median ratio and ranges of contralateral to ipsilateral fall in skin blood flow after provocative manoeuvres in unilateral hemisphere lesions and related to skin temperature. For normal subjects the ratio is largest response/smallest

\begin{tabular}{|c|c|c|c|c|}
\hline & $n$ & cough & inspiration & startle \\
\hline $\begin{array}{l}\text { Temp difference }>1{ }^{\circ} \mathrm{C} \\
\text { Motor signs }\end{array}$ & 7 & $\begin{array}{l}8 \cdot 0 \\
(2 \cdot 7-30 \cdot 0)\end{array}$ & $\begin{array}{l}5 \cdot 2 \\
(2 \cdot 0-18 \cdot 4)\end{array}$ & $\begin{array}{l}13 \cdot 0 \\
(1 \cdot 9-38 \cdot 0)\end{array}$ \\
\hline $\begin{array}{l}\text { Temp difference }<1^{\circ} \mathrm{C} \\
\text { Motor signs }\end{array}$ & 8 & $\begin{array}{l}7 \cdot 4 \\
(1 \cdot 8-34 \cdot 2)\end{array}$ & $\begin{array}{l}6 \cdot 9 \\
(1 \cdot 5-25 \cdot 3)\end{array}$ & $\begin{array}{l}15 \cdot 0 \\
(1 \cdot 5-27 \cdot 0)\end{array}$ \\
\hline No motor signs & 8 & $\begin{array}{l}0.9 \\
(0.5-1 \cdot 1)\end{array}$ & $\begin{array}{l}1 \cdot 0 \\
(0.8-1 \cdot 9)\end{array}$ & $\begin{array}{l}0 \cdot 6 \\
(0 \cdot 1-1 \cdot 0)\end{array}$ \\
\hline $\begin{array}{l}\text { Normal subjects } \\
\text { Temp difference } 0.1 \pm 0.7^{\circ} \mathrm{C}\end{array}$ & 14 & $\begin{array}{l}1 \cdot 2 \\
(1 \cdot 0-1 \cdot 6)\end{array}$ & $\begin{array}{l}1 \cdot 4 \\
(0 \cdot 7-1 \cdot 8)\end{array}$ & $\begin{array}{l}1 \cdot 1 \\
(0 \cdot 3-2 \cdot 0)\end{array}$ \\
\hline
\end{tabular}

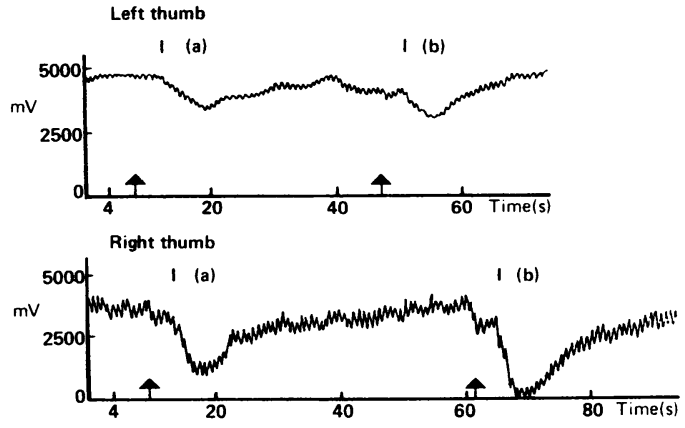

Figure 3 Reduction in skin blood flow after a cough (a) in a 56 year old man with a right homonymous hemianopia following removal of a left parieto-occipital glioma five days previously. Beginning of manoeuvre $(\uparrow)$; beginning of response (1).

patients with motor lesions despite normal breathing and absence of any provoking factors (fig 2C). All the previous observations applied to three patients who were flaccid following the removal of gliomas during the previous five days (fig 3 ).

\section{Discussion}

It has been recognised for some time that partial or complete hemiplegia occurring as the result of a cerebral insult is accompanied by vasomotor disturbances over the paralysed extremities. Some authors have attributed such changes to the peripheral effects of motor paresis ${ }^{5}$ but others have suggested that the cortex itself exerts a control over the vasomotor response. $^{6-9}$ This work supports the latter view by showing a clear asymmetry in cutaneous vasomotor reflexes in patients with unilateral cerebral lesions.

In common with other groups, ${ }^{67}$ a temperature asymmetry was found with the affected limb being warmer. Since it is known that peripheral cutaneous vasomotor fibres are predominantly, but not entirely, vasoconstrictor $^{1011}$ the observation suggests that vasodilatation is secondary to a reduction in tonic sympathetic outflow. A reduction in tonic outflow has also been found in complete tetraplegia. ${ }^{12}$

The asymmetries in CVR's were independent of any temperature difference between limbs. It is likely that the amplitudes of CVR's alter with central core and local arm temperature, with vasodilatation possible at low temperatures rather than vasoconstriction. Frontoparietal lesions may affect this sensitivity. However this study has been concerned with observing the phenomenon and in showing it to be present independently of temperature effects.

The findings, in the affected limb in unilateral motor cortex or internal capsule lesions, of raised temperature due to a presumed reduced tonic sympathetic outflow, with increased cutaneous vasomotor reflexes, suggests that a reduction in descending control has different effects on tonic thermoregulatory autonomic outflow and spinally mediated reflex outflow. In those few cases studied early in the postoperative period the increased CVR had already appeared. This suggests the asym- 
metry may be due to a "disinhibition" rather than a slow reorganisation homologous with the emergence of spasticity.

Bolton B, Carmichael EA, Sturup G. Vasoconstriction following deep inspiration. $J$ Physiol 1936;86:83-94

2 Gilliatt RW, Guttmann L, Whitteridge D. Inspiratory vasoconstriction in patients after spinal injuries. J Physiol vasoconstriction in

3 Cole JD, Mani R, Sedgwick EM. Cutaneous vasomotor reflexes following spinal cord injury in man. $J$ Physio 1985;369:134P

4 Oberg PA, Tenland T, Nilsson GE. Laser-doppler flowmetry: A non invasive and continuous method for blood flow evaluation in microvascular studies. Acta Med Scand Suppl 1983;687:17-24.

5 Johnson RH, Spalding JMK. Disorders of the autonomic nervous system. Oxford: Blackwell Scientific Publications, 1974:120

6 Chevallier PE. De la paralysie des nerfs vaso-moteurs dans l'hemiplegie, These de Paris. Paris: E Martinet, 1867.

7 Ellis LB, Weiss S. Vasomotor disturbance and oedema associated with cerebral hemiplegia. Arch Neurol Psychiatry 1936;36:363-72.

8 Gowers WR. A manual of diseases of the nervous system. London: J and A Churchill Ltd, 1886;2:77.

9 Kennard MA. Vasomotor disturbances resulting from cortical lesions. Arch Neurol Psychiatry 1935;33:537-45.

10 Blumberg H, Wallin BG. Direct evidence of neurally mediated vasodilatation in hairy skin of skin of the human mediated vasodilatation in hairy sir.

11 Hagbarth K-E, Hallin RG, Hongell AA, Torebjork HE Wallin BG. General characteristics of sympathetic activity in human skin nerves. Acta Physiol Scand 1972;84: 164-76.

12 Wallin BG, Stjernberg L. Sympathetic activity in man after spinal cord injury. Brain 1984;107:183-98.
A classic description of subacute combined degeneration of the spinal cord

Amongst the early descriptions of cord lesions in association with anaemia was Lichtheim's,' but confusion with tabes and other degenerative diseases prevailed when Leichtenstern ${ }^{2}$ described the same affection as "Progressive Pernicious Anaemia in Tabetic patients." The most assiduous account was in a 70 page paper by JS Risien Russell, FE Batten and James Collier $^{3}$ from Queen Square. They described nine patients with autopsies in seven. The illness was in three stages:

"1 A stage of slight spastic paraplegia with slight ataxy and marked subjective sensations in the lower limbs.

2 A stage of severe spastic paraplegia with marked anaesthesia of legs and trunk.

3 A stage of complete paraplegia; absent knee jerks; absolute anaesthesia; rapid wasting and loss of faradic excitability in the muscles of the paraplegic region; increase of superficial reflex excitability; absolute incontinence of both sphincters and oedema of the lower extremities and trunk.

A lengthy detailed description, illustrated by sensory charts follows. The disease appeared in the fourth and fifth decades, average age 40; four of their seven necropsy cases were female and there was a slight family history in two cases. In respect of the anaemia they noted:

“. . . some of the most typical cases presented no anaemia throughout the course ... others only late in the disease, while in other cases anaemia was an obtrusive symptom from the first and preceded the nervous symptoms by many months.'

The course was rapid, duration four and three months respectively in cases 2 and 6 , or chronic in cases 5 and 9. There were many odd features we would not today recognise as part of the illness. Cranial nerve palsies, convulsions and pyrexia developed in certain instances.
"Lightning pains in the legs occurred, and ... in all cases a severe constant dragging pain beneath the lower costal margin, always unilateral .. . Herpes occurred in two cases and cutaneous haemorrhage, in a third, in nerve root distribution . . . Most patients died within four months of losing the ability to walk. Duration varied between three months and thirty months, averages under nine months."

Pathologically: "the stress of the disease fell on the mid-dorsal region of the cord . . . very marked destruction of the white matter all round the periphery ... . not in any way limited to the long tracts. "The posterior columns, which are generally most affected, may be completely sclerosed . . . Lesions as high as the upper medulla or mid pons" (stained by Marchi and Weigert-Pal methods)...

Both "a focal destructive lesion and a system degeneration" were recognized ... In most cases the peripheral nerves were found to be normal or showed only very slight changes, but case 1 . showed very considerable degeneration.

These pathological studies are detailed and excellently illustrated. They repay minute study, rather than abbreviation here. Six theories of causation are elaborated, with a final preference for an unidentified toxin which damages both the blood and cord.

It was not until 1926 that Minot and Murphy discovered the "liver factor" which reversed pernicious anaemia, prolonged life, and later was found to contain the vital cobalamin - vitamin $B_{12}$.

JMS PEARCE

1 Lichtheim L. Verhandl des VI. Congresses f. innere Med 1887; Neurol Centrabl 1887;6:235.

2 Leichtenstern Deutsch Med Woch 1884;10:849.

Russell JSR, Batten FE, Collier J. Subacute Combined Degeneration of the Spinal Cord. Brain 1900;23:39-110. 